\title{
Alterações leucocitárias ocasionadas pelo estresse toxicológico agudo do óleo diesel em juvenis de tilápia-do-nilo
}

\section{Change in leukocyte by acute toxicological stress of diesel oil in juveniles of Nile tilapia}

\author{
Marcia Valeria Silva do Couto', Elias Fernandes de Medeiros Junior ${ }^{2}$, Cleoni Virginio da Silveira², \\ Natalino da Costa Sousa ${ }^{*}$.
}

RESUMO: O presente trabalho teve como objetivo avaliar o estresse e as alteraçóes no leucograma dos juvenis de Oreochromis niloticus submetidos à toxicidade aguda do óleo diesel. A toxicidade foi avaliada em um delineamento inteiramente casualizado com cinco diluiçôes $(20,25,30,35$ e 40\%) e um controle, ambos com três repetiçóes. Para a avaliação dos níveis glicêmicos e alteração no leucograma, foi retirado sangue por punção caudal dos peixes moribundos. Dessa forma, conclui-se que o óleo diesel pode apresentar riscos ao ecossistema aquático, provocando toxicidade aos organismos aquáticos e alterações fisiológicas.

PALAVRAS-CHAVE: alteração fisiológica; peixe; derivado de petróleo; leucograma.

\begin{abstract}
This study aimed to evaluate the stress and changes in white blood cell count of juveniles Oreochromis niloticus subjected to acute toxicity of diesel oil. The toxicity was evaluated in a completely randomized design with five dilutions $(20,25,30,35$ and 40\%) and one control, both with three replicates. For the assessment of blood glucose levels and changes in white blood cell count, blood was drawn by caudal puncture of the dying fish. It was concluded that diesel oil can present risks to aquatic ecosystem, causing toxicity and physiological changes to fish.
\end{abstract}

KEYWORDS: physiological changes; fish; derived oil; leukogram. 


\section{INTRODUÇÃO}

A pesca extrativista é uma importante atividade econômica na regiáo Norte e apresenta crescimento contínuo, alcançando 13,2\% em 2011, sendo uma das principais fontes de renda para os ribeirinhos na região amazônica (BRASIL, 2011). Essa atividade é composta das frotas industrial e artesanal (DORIA et al., 2012), constituídas por embarcaçóes motorizadas, as quais utilizam óleo diesel como o principal combustível (ALCÂNTARA et al., 2015).

O óleo diesel é um derivado de petróleo, que contém em sua composição uma complexa mistura de substâncias químicas, com cadeias longas de hidrocarbonetos aromáticos, enxofre, nitrogênio e oxigênio (SIMONATO et al., 2008; EGRES et al., 2012). O descarte ou escape desse combustível no ambiente aquático pode afetar severamente os organismos existentes, ocasionando alteraçôes teciduais e hematológicas, podendo levar à morte das espécies mais sensíveis (SIMONATO et al., 2008; SIMONATO et al., 2013; RODRIGUES et al., 2010).

A toxicidade dos derivados de petróleo está relacionada ao tamanho da cadeia de hidrocarbonetos aromáticos policíclicos (HPA) e monocíclicos (benzeno, tolueno, etilbenzeno e xileno-BTEX), que em meio aquático podem ocasionar danos mutagênicos e carcinogênicos, além de bioacumulação tecidual e alta mortalidade dos organismos atingidos (SIMONATO et al., 2008; RODRIGUES et al., 2010).

Os riscos gerados por esses compostos remetem à preocupação com o seu derramamento ou descarte residual no meio hídrico (KUBACH et al.; EGRES et al., 2012), principalmente os oriundos das embarcaçóes pesqueiras, que, mesmo quando descartados em pequena quantidade, por ocorrer de maneira contínua, atuam de forma crônica nos organismos aquáticos (SIMONATO et al., 2008; SIMONATO et al., 2013). Essa exposição toxicológica pode alterar o comportamento, a morfologia, o metabolismo, o crescimento, a reprodução e o sistema imunológico dos peixes (RODRIGUES et al., 2010; SIMONATO et al., 2013).

Nesse contexto, faz-se necessário conhecer os efeitos desse xenobiótico em organismos aquáticos, sendo os ensaios toxicológicos uma ferramenta de avaliaçáo que, associada aos parâmetros hematológicos, pode determinar as concentraçóes que ocasionam a mortalidade dos organismos e gerar diagnósticos sobre as principais alteraçôes fisiológicas ocorrentes.

Diante desse contexto, o objetivo do presente trabalho foi avaliar o estresse e as alteraçóes no leucograma dos juvenis de Oreochromis niloticus submetidos à toxicidade aguda ao óleo diesel.

\section{MATERIAL E MÉTODOS}

Os juvenis de tilápia-do-nilo (O. niloticus) foram adquiridos de um fornecedor local e aclimatados por sete dias no
Instituto Federal do Amazonas, em São Gabriel da Cachoeira, Amazonas, visando diminuir o estresse de captura. Os espécimes foram mantidos em caixas-d'água de $500 \mathrm{~L}$, com aeraçâo constante e alimentados com raçáo extrusada duas vezes ao dia, submetidos a fotoperíodo de 12 horas e densidade de 0,18 peixes por litro. Após esse período, foram realizados os testes toxicológicos preliminares, para determinar as diluiçôes de óleo diesel que causariam 0 e $100 \%$ de mortalidade. Posteriormente, foi feito o teste definitivo, seguindo recomendaçóes do Instituto Brasileiro do Meio Ambiente e dos Recursos Naturais Renováveis (IBAMA, 1987).

Para a concretização do teste definitivo, foi utilizada uma soluçấo estoque contento $400 \mathrm{~mL}$ de óleo diesel para $600 \mathrm{~mL}$ de água destilada, homogeneizada constantemente por 2 horas. O bioensaio foi realizado em delineamento inteiramente casualizado com cinco diluiçôes da soluçâo estoque (20, 25, 30, 35 e 40\% v/v) e uma controle, todos com três repetiçóes, por $96 \mathrm{~h}$ e com observaçấo da mortalidade a cada hora. Em cada recipiente com volume útil de $3 \mathrm{~L}$, foram adicionados cinco peixes $(3,19 \pm 0,39 \mathrm{~g})$. No período experimental, os parâmetros físico-químicos da água foram monitorados e mantidos nas seguintes condiçôes: oxigênio dissolvido $\left(6,54 \pm 0,49 \mathrm{mg} \cdot \mathrm{L}^{-1}\right)$, temperatura $\left(28,6 \pm 0,62^{\circ} \mathrm{C}\right)$, $\mathrm{pH}(6,42 \pm 0,52)$ e condutividade $\left(182 \pm 29,3 \mu \mathrm{S} . \mathrm{cm}^{-1}\right)$.

$\mathrm{O}$ valor de concentraçáo letal média $\mathrm{CL}\left(\mathrm{P}_{\mathrm{I}}\right)_{\text {50-96h }}$ foi determinado pelo método de Trimmed Spearman-Karber (HAMILTON et al., 1977) e classificado de acordo com a Companhia Ambiental do Estado de São Paulo (CETESB, 1987), a qual divide os xenobióticos em: muito tóxicos (quando a $\mathrm{CL}_{50}$ é menor que 25\%), tóxicos (25 a 50\%), moderadamente tóxi$\cos (51$ a $75 \%$ ), levemente tóxicos (acima de $75 \%$ ) e praticamente náo tóxicos (100\%).

Os índices glicêmicos e a contagem do leucograma foram realizados após coleta por punçáo do vaso caudal com seringas umedecidas com ácido etilenodiamino tetra-acético (EDTA) (5\%). Os níveis de glicose sanguínea foram determinados por meio do aparelho Accu-chek Performa" (Roche Diagnostics, Basileia, Suíça). Uma alíquota de sangue foi usada para as confecçôes de extensóes sanguíneas, secas ao ar e coradas pancromicamente (ROSENFELD, I947), para a contagem total de trombócitos e leucócitos, além da contagem diferencial de leucócitos.

Os dados obtidos foram submetidos à análise de normalidade (Shapiro-Wilk) e posteriormente ao teste ANOVA. Em presença de diferença significativa, foram submetidos ao teste de Tukey (5\%) para comparaçáo de médias.

Os autores declararam não terem submetido o projeto que originou esses dados ao Comitê de Ética da Universidade Federal do Pará, para avaliação. Porém, estão cientes do conteúdo das resoluçôes do Conselho Nacional de Controle de Experimentação Animal (CONCEA), órgão do Ministério da Ciência, Tecnologia, Inovações e Comunicaçôes, caso envolva animais. Os autores assumem total responsabilidade pelos dados apresentados e colocam-se à disposiçâao para possíveis questionamentos, caso necessário. 


\section{RESULTADO E DISCUSSÃO}

Durante o período experimental, foi observada $100 \%$ de mortalidade na maior diluição testada (40\%) em menos de 24 horas de exposição (Fig. 1), sendo notado aumento da mortalidade com o aumento das diluiçóes. A $\mathrm{CL}_{50-99 \mathrm{~h}}$ foi de $30,01 \%$, com limite inferior de 28,08\% e limite superior de 32,05\%, assim classificado como um produto tóxico, de acordo com a CETESB (1987).

Escassos são os estudos sobre a toxicidade dos derivados de petróleo para os peixes dulcícolas. A toxicidade do óleo diesel para juvenis de tilápia já foi relatada por NOGUEIRA et al. (2011), que constataram a exposição dos juvenis de $O$. niloticus nas diluiçóes de 0,01 e $0,05 \%$ por sete dias, verificando mortalidade de $100 \%$ dos peixes no sexto dia de experimento para a maior diluição testada. Já SCHEIN et al. (2009), realizando ensaios crônicos com alevinos de truta-arco-íris (Oncorhynchus Mykiss) e usando duas diluiçôes da fração solúvel em água de óleo diesel (0,01 e 1\%) ao longo de nove dias, determinaram concentração média de $0,05 \%$. No presente estudo, a concentração letal média a 50\% encontrada foi maior que os achados de NOGUEIRA et al. (2011) e SCHEIN et al. (2009), com mortalidade de $100 \%$ em menos de 24 horas.

O risco ambiental ocasionado pelos derivados de petróleo e a toxicidade aos organismos aquáticos podem estar relacionados com as partes solúveis desses produtos na água (SCHEIN et al., 2009; RODRIGUES et al., 2010). SIMONATO et al. (2008) e RODRIGUES et al. (2010) aportam que é possível que a mortalidade decorrente da toxicidade do óleo diesel esteja associada com as alteraçóes fisiológicas e morfológicas, tais como hiperplasia, aneurisma e necrose nos tecidos, podendo afetar o comportamento dos peixes.

No presente estudo foram observadas alterações comportamentais como nataçáo errática, agitação e posicionamento dos peixes na superfície da água. Essas alteraçóes comportamentais são uma das respostas ao estresse ocasionado pela exposiçáo dos animais ao produto tóxico, causando alteraçôes nos valores glicêmicos, que é uma resposta secundária utilizada como indicador de estresse em peixes (WINKALER et al., 2001; SILVA et al., 2012; CHAGAS et al., 2012). Neste estudo foi visto aumento ( $\mathrm{p}<5 \%)$ na glicemia (Fig. 2) dos peixes a partir da terceira diluição (30\%), e na diluição de $40 \%$ houve acréscimo de 73,52\% no nível glicêmico dos juvenis de tilápia-do-nilo em relaçáo ao controle $\left(42,5 \pm 2,51 \mathrm{mg} \cdot \mathrm{dL}^{-1}\right)$.

SIMONATO et al. (2008) observaram aumento de $120 \%$ nos níveis glicêmicos em juvenis de Prochilodus lineatus após 96 horas de exposição dos animais à fraçáo solúvel em água do óleo diesel em comparação ao controle $\left(22,00 \pm 1,00 \mathrm{mg} \cdot \mathrm{dL}^{-1}\right)$. ROSTAM; SOLTANI (2016) apontaram aumento nos níveis glicêmicos de Huso huso na exposição crônica nas concentraçóes de petróleo 0,$218 ; 0,327$ e $0,436 \mathrm{mg} . \mathrm{L}^{-1}$ e registraram aumento na glicemia de 12,06; 17,24 e 25,86\%, respectivamente, em relaçáo ao tratamento controle $\left(58 \pm 3,00 \mathrm{mg} \cdot \mathrm{dL}^{-1}\right)$ durante 14 dias de experimento. Assim, o aumento nos valores glicêmicos dos peixes expostos aos xenobióticos pode ter ocorrido pela estimulação das catecolaminas, mobilizando o aumento à glicogenólise, de forma a gerar energia para uma ação rápida dos animais a um agente estressor (MOREIRA et al., 2011; CHAGAS et al., 2012).

Quanto aos parâmetros sanguíneos, o trombócito é um tipo de célula que apresenta funçôes importantes no sistema imune dos peixes, atuando na homeostasia, realizando fagocitose e até mesmo migrando para sítios inflamatórios (GARCIA et al., 2012). Ocorreu aumento $(\mathrm{p}<5 \%)$ no número de trombócitos nas diluiçóes de 35 e $40 \%$, registrando 40,01 $\pm 4,09$ células $\times$ $10^{3} \cdot \mu \mathrm{L}^{-1}$ e $38,40 \pm 5,45$ células $\times 10^{3} \cdot \mu \mathrm{L}^{-1}$, respectivamente, em relaçáo ao grupo controle (Fig. 3).

A exposição dos peixes aos derivados de petróleo pode ocasionar inflamação dos órgãos que estáo em contato direto com esses derivados, como as brânquias. Portanto, o aumento de trombócitos nos peixes pode ter ocorrido em busca do retorno homeostático, com a migração dessas células para o local afetado (SCHALCH et al., 2015), pois a inflamação é uma resposta dos organismos com o intuito de aumentar o fluxo de sangue para a migração de células fagocíticas e com função de coagulação para o local danificado por meio da vasodilataçáo (SALIU; SALAMI, 20I3).

No tocante aos leucócitos totais, foi observado aumento ( $\mathrm{p}<5 \%$ ) na última diluição (40\%), com contagem média de 58,4

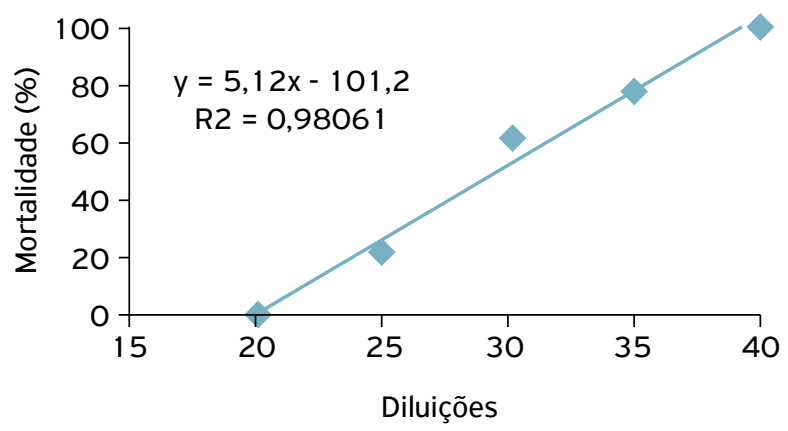

Figura 1. Mortalidade de juvenis de tilápia-do-nilo expostos a diferentes diluições de óleo diesel.

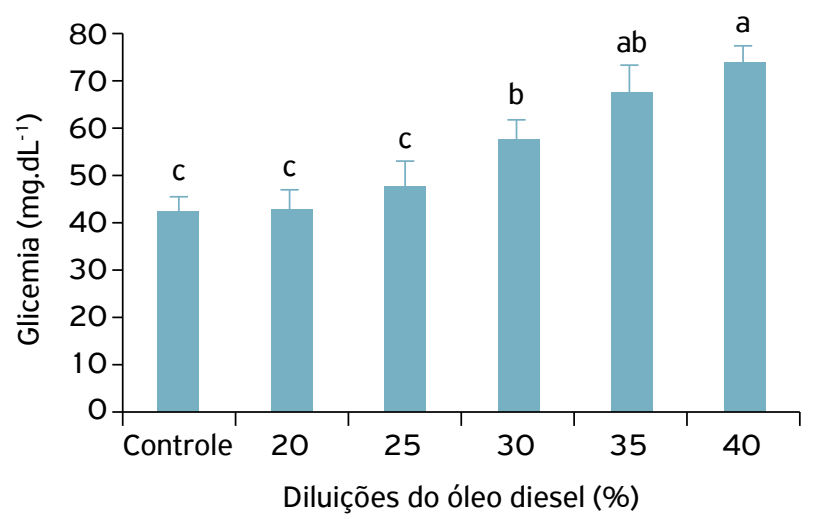

Figura 2. Valores glicêmicos de juvenis de tilápia-do-nilo expostos a diferentes diluições de óleo diesel. Valores nas barras (média \pm desvio padrão) seguidas de letras diferentes apresentam diferença estatística pelo teste Tukey $(p<5 \%)$. 
$\pm 6,82$ células $\times 10^{3} \cdot \mu \mathrm{L}^{-1}$ em relaçáo ao controle $(42,8 \pm 4,57$ células $\left.\times 10^{3} \cdot \mu \mathrm{L}^{-1}\right)$. Essas células são responsáveis pela defesa do organismo, que pode ser modulada de acordo com o estímulo aos quais os animais estáo submetidos (MARINHO et al., 2015).

No presente estudo foi observada redução $(\mathrm{p}<5 \%)$ de linfócitos nas diluiçóes de 35 e 40\%, com contagem média de $24,3 \pm 3,37$ células $\times 10^{3} \cdot \mu \mathrm{L}^{-1}$ e 24,1 $\pm 2,44$ células $\times 10^{3}$. $\mu \mathrm{L}^{-1}$, respectivamente. Em contrapartida, houve aumento ( $\mathrm{p}<5 \%)$ no número de monócitos na maior diluição (40\%), com valor médio de $24,08 \pm 3,15$ células $\times 10^{3} \cdot \mu \mathrm{L}^{-1}$ em relação ao controle (Tabela 1).

Os linfócitos são células responsáveis pela produção de anticorpos e pela parte humoral em peixes (SILVA et al., 2012). Pode-se inferir, neste estudo, que a sua redução está associada com o estresse ocasionado pelo óleo diesel, tendo em vista que o estresse prolongado pode provocar imunossupressão, debilitando o sistema imunológico dos organismos submetidos a xenobióticos (FUJIMOTO et al., 2012). Similaridade foi percebida por ALI et al. (2014), que observaram redução no número de linfócitos do tecido sanguíneo de Fundulus grandis expostos ao petróleo.

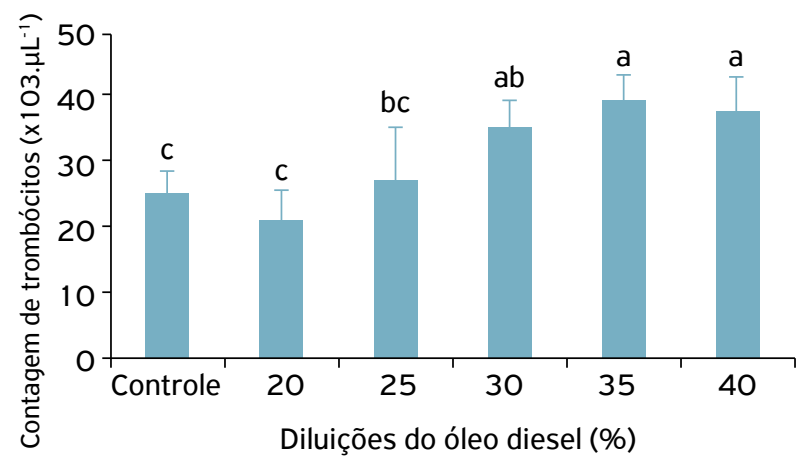

Figura 3. Contagem de trombócitos em juvenis de tilápia expostos a diferentes diluições de óleo diesel. Valores nas barras (média \pm desvio padrão) seguidas de letras diferentes apresentam diferença estatística pelo teste Tukey $(p<5 \%)$.
O aumento de monócitos possivelmente ocorreu pelo estímulo dos órgãos hematopoiéticos em resposta à inflamação ocasionada pela exposição ao óleo diesel, sendo uma célula com funçôes fagocitárias importantes no sistema imune dos peixes (DIAS et al., 2011), podendo migrar do tecido sanguíneo para o tecido de órgãos danificados. Logo, o aumento dessa célula possivelmente dá-se com o intuito de agir como macrófago nos tecidos danificados, concordando com ALI et al. (2014), que constataram aumento de monócito $F$ grandis.

No presente estudo não foi observada diferença na contagem de neutrófilos nem de basófilos entre os tratamentos. HEDAYATI; JAHANBAKHSHI (2013), que observaram o efeito do óleo diesel em juvenis de $H$. huso, registraram a presença de linfócitos, neutrófilos e eosinófilos no tecido sanguíneo, mostrando que a exposiçáo dos juvenis por 48 horas ao xenobiótico ocasionou redução de linfócitos e aumento de neutrófilos. Logo, o derramamento ou descarte inadequado dos derivados de petróleo no ambiente aquático pode ocasionar inflamação nos organismos, alterando possivelmente os parâmetros hematológicos dos peixes (RODRIGUES et al., 2010; SIMONATO et al., 2013). Assim, o aumento da glicemia com a crescente adição de óleo diesel é uma resposta fisiológica dos peixes ao desequilíbrio homeostático, na tentativa de se adaptar às condiçôes adversas às quais estão submetidos.

\section{CONCLUSÕES}

O estresse ocasionado pelo óleo diesel apresenta-se como um risco ambiental para os organismos aquáticos, por se tratar de um produto tóxico para a tilápia.

A exposição dos peixes ao xenobiótico provoca desequilíbrio homeostático capaz de reduzir o número de linfócitos e aumentar o de monócitos nos peixes, ocasionado pela toxicidade ao óleo diesel.

Tabela 1. Contagem total e diferencial de leucócitos de juvenis de tilápia-do-nilo submetidos a diferentes diluições de óleo diesel.

\begin{tabular}{|c|c|c|c|c|c|c|}
\hline & \multicolumn{6}{|c|}{$\begin{array}{c}\text { Diluições de óleo diesel } \\
\text { (média } \pm \text { DP) }\end{array}$} \\
\hline & Controle & $20 \%$ & $25 \%$ & $30 \%$ & $35 \%$ & $40 \%$ \\
\hline $\begin{array}{l}\text { Leucócitos } \\
\left(x 10^{3} \cdot \mu L^{-1}\right)\end{array}$ & $42,80 \pm 4,57 b$ & $42,60 \pm 6,35 b$ & $47,70 \pm 9,93 a b$ & $49,90 \pm 3,99 a b$ & $50,90 \pm 5,04 a b$ & $58,40 \pm 6,82^{a}$ \\
\hline $\begin{array}{l}\text { Linfócitos } \\
\left(x 10^{3} \cdot \mu \mathrm{L}^{-1}\right)\end{array}$ & $31,20 \pm 4,41 a$ & $31,4 \pm 3,84 a$ & $30,40 \pm 3,51 a$ & $27,90 \pm 2,06 a b$ & $24,30 \pm 3,37 b$ & $24,10 \pm 2,44 b$ \\
\hline $\begin{array}{l}\text { Monócitos } \\
\left(x 10^{3} \cdot \mu \mathrm{L}^{-1}\right)\end{array}$ & $5,60 \pm 1,24 d$ & $4,75 \pm 1,81 d$ & $8,54 \pm 3,84 c d$ & $12,50 \pm 1,99 b c$ & $16,60 \pm 2,60 b$ & $24,00 \pm 3,15^{a}$ \\
\hline $\begin{array}{l}\text { Neutrófilos } \\
\left(x 1 O^{3} \cdot \mu \mathrm{L}^{-1}\right)\end{array}$ & $6,92 \pm 0,81 a$ & $6,33 \pm 4,46 a$ & $8,62 \pm 3,15 a$ & $9,40 \pm 4,20 a$ & $9,75 \pm 3,57 a$ & $8,77 \pm 3,43 a$ \\
\hline $\begin{array}{l}\text { Basófilos } \\
\left(x 10^{3} \cdot \mu L^{-1}\right)\end{array}$ & $0,09 \pm 0,07 a$ & $0,09 \pm 0,07 a$ & $0,13 \pm 0,10 a$ & $0,09 \pm 0,05 a$ & $0,15 \pm 0,10 a$ & $0,14 \pm 0,06 a$ \\
\hline
\end{tabular}

DP: desvio padrão; letras diferentes nas linhas indicam diferença significativa pelo teste de Tukey (5\%). 

REFERÊNCIAS

ALCÂNTARA, N.C.; GONÇALVES, G.S.; BRAGA, T.M.P.; SANTOS, S.M.; ARAÚJO, R.L.; PANTOJA-LIMA, J.; ARIDE, P.H.R.; DE OLIVEIRA, A.T. Avaliação do desembarque pesqueiro (20092010) no município de Juruá, Amazonas, Brasil. Biota Amazônia (BioteAmazonie, Biota Amazonia, Amazonian Biota), v.5, n.1, p.37-42, 2015.

ALI, A.O.; HOHN, C.; ALLEN, P.J.; FORD, L.; DAIL, M.B.; PRUETT, S.; PETRIE-HANSON, L. The effects of oil exposure on peripheral blood leukocytes and splenic melano-macrophage centers of Gulf of Mexico fishes. Marine Pollution Bulletin, v.79, n. 1-2, p.87-93, 2014.

BRASIL. Ministério da Pesca e Aquicultura. Boletim Estatístico da pesca e aquicultura. Brasília, 2011 .60p.

CHAGAS, E.C.; ARAÚJO, L.D.D.; GOMES, L.D.C.; MALTA, J.C.D.O.; VARELLA, A.M.B. Effect of sodium chloride on physiological responses and monogeneancontrol in tambaqui (Colossoma macropomum). Acta Amazonica, v.42, n.3, p.439-444, 2012.

COMPANHIA AMBIENTAL DO ESTADO DE SÃO PAULO (CETESB). Aplicação de microrganismos e culturas celulares na avaliação da toxicidade de efluentes industriais na região da grande São Paulo. São Paulo: CETESB, 1987. 146p.

DIAS, D.D.C.; TACHIBANA, L.; SERIANI, R.; SANTOS, A.A.; RANZANIPAIVA, M.J.T.; ROMAGOSA, E. Macrophagic migration time in matrinxã, Brycon amazonicus, through inoculation of yeast, Saccharomyces cerevisiae, technique. Acta Amazonica, v.41, n.3, p.421-424, 2011.

DORIA, C.R.D.C.; RUFFINO, M.L.; HIJAZI, N.C.; CRUZ, R.L.D. A pesca comercial na bacia do rio madeira no estado de Rondônia, Amazônia brasileira. Acta Amazonica, v.42, n. 1, p.29-40, 2012.

EGRES, A.G.; MARTINS, C.C.; DE OLIVEIRA, V.M.; DA CUNHA LANA, P. Effects of an experimental in situ diesel oil spill on the benthic community of unvegetated tidal flats in a subtropical estuary (Paranaguá Bay, Brazil). Marine Pollution Bulletin, v.64, n.12, p.2681-2691, 2012.

FUJIMOTO, R.Y.; GABBAY, M.I.; ANJOS, E.C.S.; CARRASCHI, S.P.; CRUZ, C. Toxicidade e risco ambiental da oxitetraciclina e efeito em leucócitos de Mato Grosso (Hyphessobrycon eques). Ecotoxicology and Environmental Contamination, v.7, n.2, p. 11 $15,2012$.

GARCIA, F.; SCHALCH, S.H.C.; ONAKA, E.M.; FONSECA, F.S.; BATISTA, M.P. Hematology of Nile tilapia fed supplementation with algae challenged by acute and chronic stress. Arquivo Brasileiro de Medicina Veterinária e Zootecnia, v.64, n. 1, p.198-204, 2012.

HAMILTON, M.A.; RUSSO, R.C.; THURSTON, R.V. Trimmed spearmankarber method for estimating median lethal concentrations in toxicity bioassays. Environmental Science \& Technology, v. 11 , n.7, p.714-719, 1977.
HEDAYATI, A.; JAHANBAKHSHI, A. Hematotoxic effects of direct infusion of crude diesel oil on juvenile great sturgeon Husohuso. Comparative Clinical Pathology, v.22, n.6, p.1117$1122,2013$.

INSTITUTO BRASILEIRO DO MEIO AMBIENTE E DOS RECURSOS NATURAIS RENOVÁVEIS (IBAMA). Avaliação da toxicidade aguda para peixes. parte d.3. In: IBAMA. Manual de testes para avaliação de ecotoxicidade de agentes químicos. Brasília: IBAMA, $1987.23 p$.

KUBACH, K.M.; SCOTT, M.C.; BULAK, J.S. Recovery of a temperate riverine fish assemblage from a major diesel oil spill. Freshwater Biology, v.56, n.3, p.503-518, 2011.

MARINHO, R.D.G.B.; TOSTES, L.V.; BORGES, M.; YOSHIOKA, E.T.O.; TAVARES-DIAS, M. Respostas hematológicas de Arapaima gigas (Pisces: Arapaimidae) parasitados naturalmente por protozoários e metazoários. Biota Amazônia (Biote Amazonie, Biota Amazonia, Amazonian Biota), v.5, n. 1, p.105$108,2015$.

MOREIRA, A.G.L.; TEIXEIRA, E.G.; MOREIRA, R.L.; FARIAS, W.R.L. Glicose plasmática em juvenis de tilápia do Nilo anestesiados com óleo de cravo. Revista Brasileira de Saúde e Produção Animal, v.12, n.3, p.794-804, 2011.

NOGUEIRA, L.; RODRIGUES, A.C.F.; TRÍDICO, C.P.; FOSSA, C.E.; DE ALMEIDA, E.A. Oxidative stress in Niletilapia (Oreochromis niloticus) and armoredcatfish (Pterygoplichthys anisitsi) exposedto diesel oil. Environmental monitoring and assessment, v. 180, n. 1 4, p.243-255, 2011.

RODRIGUES, R.V.; MIRANDA-FILHO, K.C.; GUSMÃO, E.P.; MOREIRA, C.B.; ROMANO, L.A.; SAMPAIO, L.A. Deleterious effects of water-soluble fraction of petroleum, diesel and gasoline on marine pejerreyodontesthesargentinensis larvae. Science of the Total Environment, v.408, n.9, p.20542059, 2010.

ROSENFELD, G. Corante pancrômico para hematologia e citologia clínica. Nova combinação dos componentes do May-Grünwald e do Giemsa num só corante de emprego rápido. Memórias do Instituto Butantan, v.20, n.1, p.329334, 1947.

ROSTAM, H.A.K.; SOLTANI, M. The effect of chronic crude oil exposure on some hematological and biochemical parameters of juvenile Beluga (Huso huso Linnaeus, 1758). International Journal of Aquatic Science, v.7, n.2, p.73-86, 2016.

SALIU, J.K.; SALAMI, A.S. Drilling fluid and diesel fuel induced histopathological alterations in the gill and liver tissue of Oreochromis niloticus. Research in Environment and Life Sciences, v.6, n.3, p.73-78, 2013. 
SCHALCH, S.H.C.; ABIMORAD, E.G.; ONAKA, E.M.; FONSECA F.S.; GARCIA, F.; CASTELLANI, D. Parâmetros hematológicos de tilápias (Oreochromis niloticus) alimentadas com dieta suplementada de cogumelo Agaricus blazei. Bioikos, v.29, n. 1, v.29-34, 2015.

SCHEIN, A.; SCOTT, J.A.; MOS, L.; HODSON, P.V. Oil dispersion increases the apparent bioavailability and toxicity of diesel to rainbow trout (Oncorhynchusmykiss). Environmental Toxicology and Chemistry, v.28, n.3, p.595-602, 2009.

SILVA, R.D.D.; ROCHA, L.O.; FORTES, B.D.A.; VIEIRA, D.; FIORAVANTI M.C.S. Parâmetros hematológicos e bioquímicos da tilápia-doNilo (Oreochromis niloticus) sob estresse por exposição ao ar. Pesquisa Veterinária Brasileira, v.32, n. 1, p.99-107, 2012.
SIMONATO, J.D.; FERNANDES, M.N.; MARTINEZ, C.B. Physiological effects of gasoline on the fresh water fish Prochilodus lineatus (Characiformes: Prochilodontidae). Neotropical Ichthyology, v. 11 , n.3, p.683-691, 2013.

SIMONATO, J.D.; GUEDES, C.L.; MARTINEZ, C.B. Biochemical, physiological, and histological changes in the neotropical fish Prochilodus lineatus exposed to diesel oil. Ecotoxicology and Environmental Safety, v.69. n. 1, p.112-120, 2008.

WINKALER, E.U.; DAS GRAÇAS SILVA, A.; GALINDO, H.C.; DOS REIS MARTINEZ, C.B. Biomarcadores histológicos e fisiológicos para o monitoramento da saúde de peixes de ribeirões de Londrina, Estado do Paraná. Acta Scientiarum Biological Sciences, v.23, n.2, p.507-514, 2001. 